\title{
RETRIEVAL OF OZONE TOTAL COLUMNS OVER ÉVORA-PORTUGAL USING REMOTE SENSING INSTRUMENTS DURING 2007-2011
}

\author{
A. F. Domingues ${ }^{\text {a }}$ *, D. Bortoli ${ }^{\text {a b }}$, A.M.Silva ${ }^{\text {a }, c}$, P. Kulkarni ${ }^{\text {a }}$, R. Mendes ${ }^{\text {a }}$ \\ ${ }^{a}$ Geophysics Centre of Évora - University of Évora (CGE-UE), Rua Romão Ramalho, 59, 7000 Évora, Portugal - \\ ana.filipa.domingues@gmail.com; pavannpl@yahoo.co.in; rrbmendes@hotmail.com \\ ${ }^{\mathrm{b}}$ Institute of Atmospheric Sciences and Climate (ISAC-CNR), Via Gobetti 101, 40129 Bologna Italy - d.bortoli@isac.cnr.it \\ ${ }^{c}$ Department of Physics, University of Évora, Rua Romão Ramalho 59, 7000 Évora, Portugal - asilva@uevora.pt
}

KEY WORDS: Ozone, SPATRAM, Remote Sensing, spectromer, DOAS, TOC

\begin{abstract}
:
The present study deals with the retrieval of Ozone $\left(\mathrm{O}_{3}\right)$ Total Column (TOC) and analysis of its variability over the Observatory of the Geophysics Centre of Évora (CGE-UE) -Portugal $\left(38.5^{\circ} \mathrm{N} ; 7.9^{\circ} \mathrm{W}, 300 \mathrm{~m}\right.$ a.s.1.) for the period comprised 2007-2011. The data presented in this study are obtained applying the Differential Optical Absorption Spectroscopy (DOAS) methodology to the measurements of diffused spectral sky radiation carried out along the zenith direction performed with the multipurpose UV-Vis. Spectrometer for Atmospheric Tracers Monitoring (SPATRAM) in the 250-900 nm spectral range. This ground-based spectrometer is installed at CGE-UE performing daily and automatic measurements since 2004. Other products of this scanning spectrometer are the vertical profiles of some trace gases (e.g. $\mathrm{NO}_{2}$ ) and monitoring of air quality. The $\mathrm{O}_{3}$ retrieved with the SPATRAM instrument confirm the typical seasonal cycle for middle latitudes reaching the maximum during the spring and the minimum during the autumn. The ground-based results obtained for $\mathrm{O}_{3}$ column are also compared with data from SCanning Imaging Absorption spectroMeter for Atmospheric CHartographY (SCIAMACHY) and Global Ozone Monitoring Experiment (GOME) instruments aboard ENVISAT and ERS-2 satellites, respectively. The results show a good agreement between the datasets. The main reasons for the observed differences are discussed.
\end{abstract}

\section{INTRODUCTION}

The rapid acceleration of the concern about a new range of global environmental problems led to real advances in related technologies for the acquisition and processing of environmental data in "real or near real-time", even from remote locations. This progress provides the assessment of data related to the atmosphere and climate, like trace gases and aerosol concentration and clouds, besides the dynamic and meteorological information of the atmosphere (Laj et al. 2009). Nowadays the monitoring of the atmosphere is carried on by means of 'in-situ' and Remote Sensing (RS) measurements obtained from ground-based instruments, balloons, airborne or satellite based equipments. The data-sets acquired with all these instruments and sensors enable the monitoring of the atmosphere and can be kept for present and future prospect studies. In a so complex system as the Earth's Atmosphere compared by Seinfeild et Pandis, 2006 "to an enormous chemical reactor in which a myriad of species are continually being introduced and removed over a vast array of spatial and temporal scales" the need of short and long term observations are evident since atmospheric processes are still far from being entirely understood.

The main motivation for accomplishing this study is the importance of monitoring the trace compounds, namely $\mathrm{O}_{3}$, in the atmosphere due to their major role in the atmospheric processes despite their low concentrations. This work is focused in the retrieval of Total Ozone Columns (TOC) with remote sensing instruments (ground-based and satellite equipments) for the period of 2007-2011 in Évora-Portugal

\section{MEASUREMENT SITE AND REMOTE SENSING INSTRUMENTS}

Figure 1 a) shows the location of the Observatory of Geophysics Centre of Évora situated in Évora. Located in the interior of Portugal, this city can be considered as a continental rural site. Évora is placed at about $130 \mathrm{~km}$ eastward from the Lisbon area and about $100 \mathrm{~km}$ westward from Badajoz (Spain). Figure $1 \mathrm{~b}$ ) c) illustrates the ground based instrument system used to perform the spectral measurements constituted by the Spectrometer for Atmospheric Tracers Monitoring (SPATRAM) instrument (Figure $1 \mathrm{~b})$ ), and the Vertical Looking Device (VELOD) ( Figure 1c)). This latter is a small telescope coupled to the spectrometer to collect solar radiation in the zenith direction. The SPATRAM system measures the zenith scattered radiation in the $200-900 \mathrm{~nm}$ spectral range. The main products are the total column and the vertical profiles of $\mathrm{NO}_{2}$ and $\mathrm{O}_{3}$. The core of SPATRAM is the monochromator which allows for the decomposition of light in several wavelengths using a grating by Jobin-Yvon of 1200 grooves $/ \mathrm{mm}$ with a typical dispersion of $2.4 \mathrm{~nm} / \mathrm{mm}$ at $300 \mathrm{~nm}$ ( Domingues, 2011). The complete description of the instrument and working method is presented in the works of Bortoli, 2005; Bortoli et al., 2009; Bortoli et al., 2009.

The ground-based results obtained were compared with data from SCanning Imaging Absorption spectroMeter for Atmospheric CHartographY (SCIAMACHY) and Global Ozone Monitoring Experiment (GOME) instruments aboard ENVISAT and ERS-2 satellites, respectively.

\footnotetext{
* Corresponding author.
} 

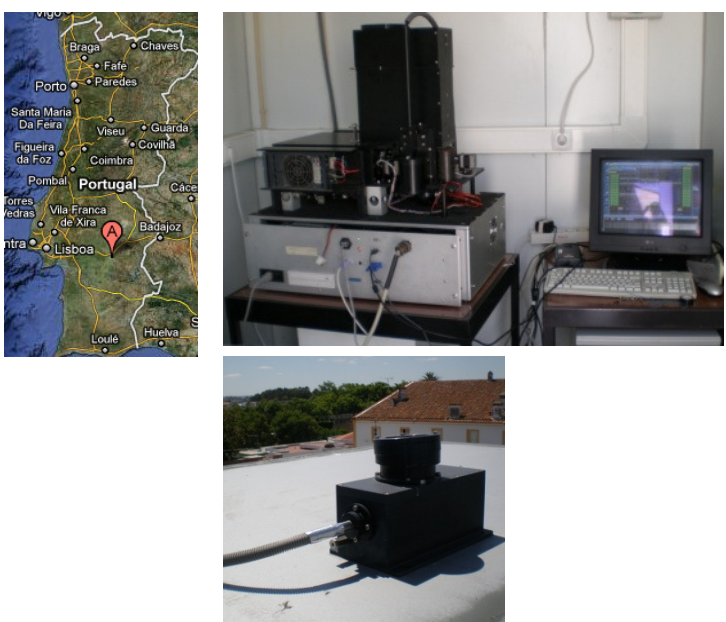

Figure 1. a) The location of Évora city in mainland Portugal. b) The SPATRAM instrument installed in the Observatory of the Geophysics Centre of Évora $\left(38.5^{\circ} \mathrm{N} ; 7.9^{\circ} \mathrm{W}, 300 \mathrm{~m}\right.$ a.s.1.). c)

The VELOD telescope (source: Domingues, 2011).

\section{METHODOLOGY}

The Differential Optical Absorption Spectroscopy (DOAS) algorithms used for the retrieval of the mean trace gas concentrations along the optical path of measure (the Slant Column Density - SCD) are presented as follows.

First of all the SPATRAM high resolution spectral data suffers a pre-processing procedure. After that it is possible to apply the DOAS method to the SPATRAM datasets using the DOAS Master Equation (Equation 1), based on the Beer-Lambert Law.

$$
\ln \left(\frac{I_{0}\left(\lambda, \theta_{\min }\right)}{I_{s}(\lambda, \theta)}\right)-\ln \left(\frac{I_{0}\left(\lambda, \theta_{\min }\right)}{I_{s}(\lambda, \theta)}\right)=\Sigma_{g}\left(\sigma_{g}(\lambda)-\overline{\sigma_{g}(\lambda)}\right) \sum_{C D}(\theta)
$$

\section{where}

$I_{0}\left(\lambda, \theta_{\min }\right)=$ reference spectrum obtained at local noon

$I_{s}(\lambda, \theta)=$ spectrum measured for different condition of SZA

$\sigma_{g}(\lambda)=$ the absorber's cross sections

$\theta=$ solar zenith angle

$\theta_{\min }=$ solar zenith angle at the local noon

$S C D_{g}(\theta)=$ slant column densities of the $g^{\text {th }}$ absorber

The superscript represents the high pass filter operator removing the low frequency features of the spectral series. Equation 1 is usually solved in a suitable wavelength interval that includes strong differential absorption structures of the trace gases of interest. To retrieve the $\mathrm{O}_{3} \mathrm{SCD}$, the DOAS algorithms were applied in the $320-340 \mathrm{~nm}$ spectral range. And the data obtained with the SPATRAM instrument comprises all the SZA between the highest daily solar elevations (which corresponds to the minimum SZA) down to approximately $93^{\circ}$ of SZA.

The final product resulting from the application of DOAS algorithms to SPATRAM data are the O3 SCD. Actually, from the definition of the DOAS Master Equation, the SCD are differences between the content of the absorber in the analysed spectrum and the amount of the considered compound in the reference spectrum. Consequently, the SCD are effectively the DSCD (Differential Slant Column Density), therefore the choice of the reference spectrum and the quantification of absorber's content in it, are crucial tasks. The reference spectrum -
$I_{0}\left(\lambda, \theta_{\min }\right)$ - used for the DOAS analysis has to be measured in optimal atmospheric conditions (sunny day without clouds) gathered at local noon. At mid-latitudes, to estimate the content of the analyzed compound in the reference spectrum $\left(S C D_{I_{0}}\left(\lambda, \theta_{\min }\right)\right)$ the Langley plots of the retrieved values during one day, before the local noon (AM) and after the local noon (PM) versus the series of the calculated AMF values are usually used. The $S C D_{g}(\lambda, \theta)$ can finally be calculated as follows in Equation 2.

$$
S C D_{g}(\lambda, \theta)=D S C D_{g}(\lambda, \theta)+S C D_{I_{0}}\left(\lambda, \theta_{\min }\right)
$$

Since the SCD is dependent of the light path it is necssary to convert this quantity into a Vertical Column Density ( VCD) in order to remove the light path dependence. This procedure is important because allows for the comparison of datasets from different instruments. The SCD to VCD conversion is made by means of Equation 3, where is introduced the concept of Air Mass Factor ( AMF). The AMF can be seen as a geometrical factor, function essentially of the Sun's elevation and of the wavelength, and it is defined as follows:

$$
A M F_{g}(\theta, \lambda)=S C D_{g}(\theta, \lambda) / V C D_{g}(\theta, \lambda)
$$

The AMF is computed by means of a Radiative Transfer Model (RTM), in this case the Atmospheric Model for Enhancement Factor Computation (AMEFCO). AMEFCO model was developed at ISAC - CNR and it is based on the Intensity Weighted Optical Path (IWOP) approach (Slusser et al.,1996). The AMEFCO is a single-scattering model using ray tracing in a spherical 2-D atmosphere (profile variation with SZA) with optical paths integrated over individual shells. Light refraction is not included. (Petrioli et al., 2002) .

\section{RESULTS}

\subsection{Stratospheric $\mathrm{O}_{3}$ seasonal variation}

The typical distribution of TOC retrieved at Évora is in accordance with the literature for the mid-latitudes. From Figure 2 it is possible to point out a clear seasonal trend of the plotted values, following a sinusoidal pattern due to relation between solar activitiy and $\mathrm{O}_{3}$ photochemical behaviour. The total ozone maximums are observed during Spring and the minimums in the Autumn due mainly to dynamic factors such as the Brewer Dobson circulation from tropical regions to the pole. This circulation is maximum during the Spring season, which correspond also to the higher $\mathrm{O}_{3}$ formation in tropical regions leading to the enhancement of the $\mathrm{O}_{3}$ concentration during that season. It is also visible the strong seasonal variability of the diurnal $\mathrm{O}_{3}$ total columns. In the years 2008 and 2010 the Autumn and Spring TOC values are lower than the ones registered in the same season of the other analyzed period. This variability can be caused by dynamical and chemical factors such as the variability in the Brewer Dobson circulation, the possible intrusion of aerosols (e.g. dust from Saharan desert, or forest fire type, eruptions), the variation in solar cycle. 


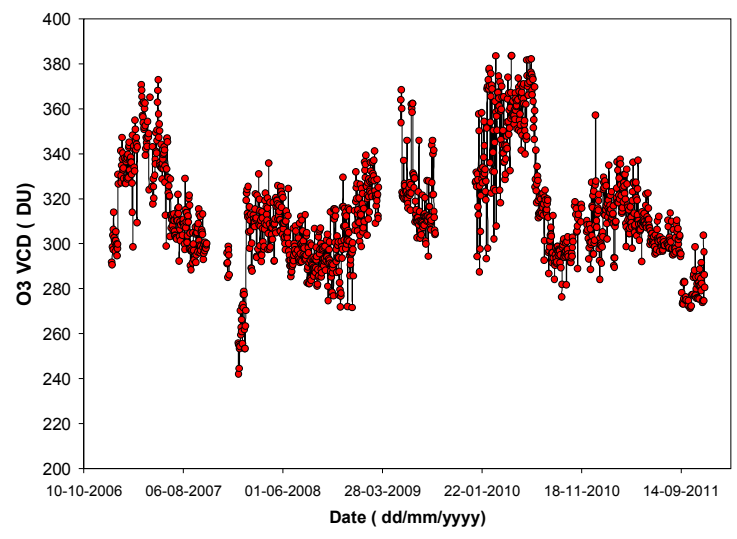

Figure 2. Time series of the $\mathrm{O}_{3} \mathrm{VCD}$ obtained with the SPATRAM equipment installed at Évora Observatory during 2007 -2011 period.

The time series obtained with SPATRAM and presented in this study are incomplete since the instrument participated in field campaigns outside Évora city .

\subsection{SPATRAM vs Satellite data}

The satellite data used for comparison with SPATRAM TOC are from SCIAMACHY and GOME. The description of the products used is presented as following:

1. The ESA usable algorithm for SCIAMACHY is called "Total Ozone retrieval scheme for SCIAMACHY based on the OMI DOAS algorithm" or "TOSOMI" (Eskes at al., 2006) and subsequently in GOME algorithm "TOGOMI" (Valks et al., 2004). This algorithm allows for the retrieval of Ozone columns from SCIAMACHY and was developed by the Royal Netherlands Meteorological Institute (KNMI). A complete description of the algorithm can be found at Eskes et al., 2006. TOSOMI product is freely available over several locations including Évora Observatory. Ozone data can be downloaded at: http://www.temis.nl/protocols/o3col/data/scia/overpass_v2 /Evora_Observatory tosomi.dat.

2. The GOME dataset is available from 1995 to 2011. For the Évora Observatory the data is freely available at http://www.temis.nl/protocols/o3col/data/gome/overpass/E vora_Observatory_togomi.dat for the considered period. The algorithm used for measuring trace gases that is current in operation is the GOME total ozone algorithm TOGOMI and was developed under ESA supervision by the German Aerospace Centre (DLR). More information about the algorithm can be found at literature (Valks et al., 2004).

In Figure 3 the two datasets (SPATRAM and SCIAMCAHY) are plotted versus time for the period of study.
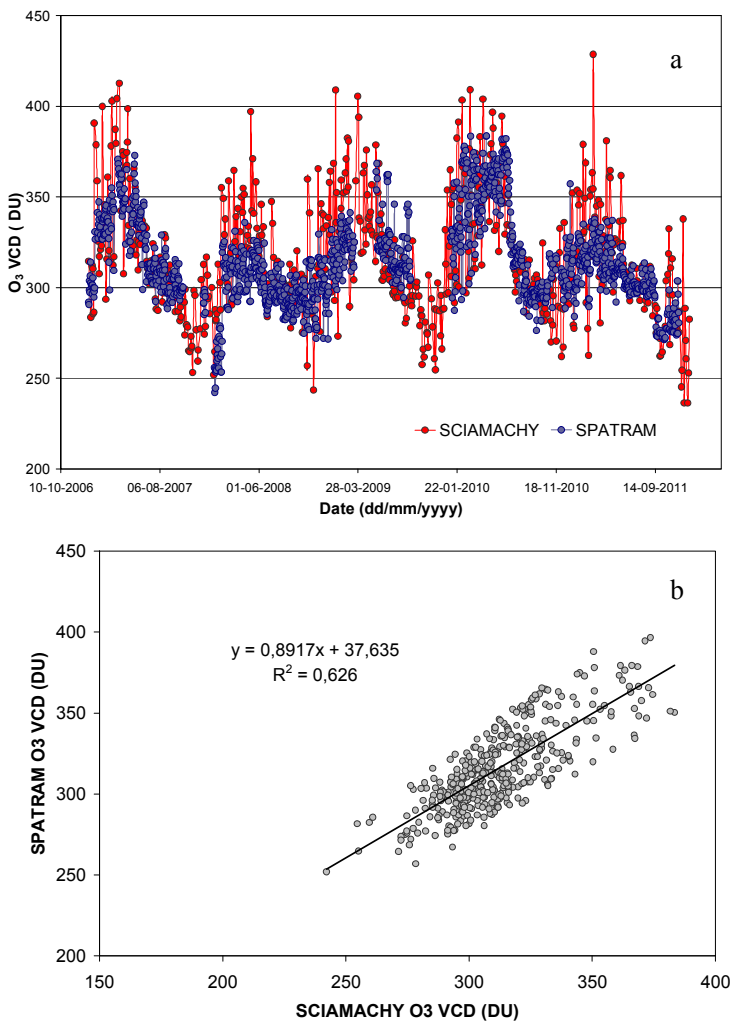

Figure 3. a) Time series of the $\mathrm{O}_{3}$ VCD obtained with the SPATRAM equipment installed at Évora Observatory during 2007-2011, and the $\mathrm{O}_{3}$ data from the SCIAMACHY instrument aboard the ENVISAT satellite. b) Scatter plot of the $\mathrm{O}_{3}$ data from the SCIAMACHY instrument (TOSOMI product) versus SPATRAM data retrieved at Évora Observatory for the same period.

Figure 4 shows the comparison of SPATRAM and GOME datasets.

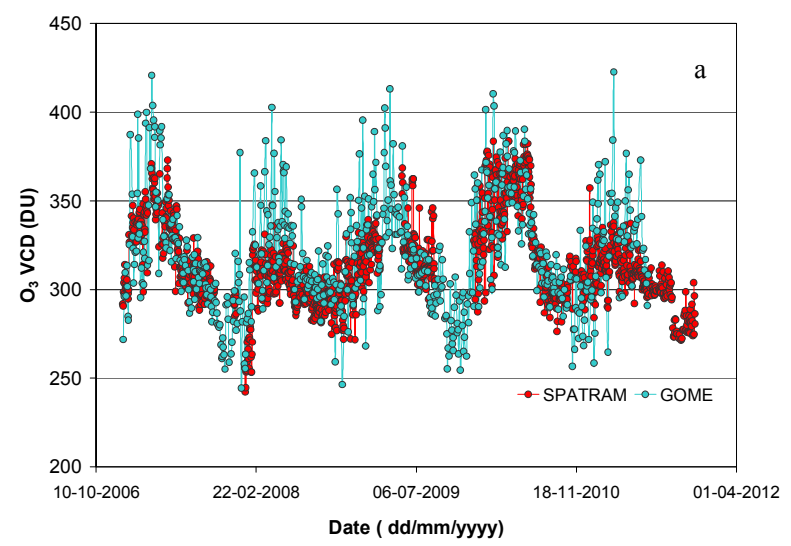




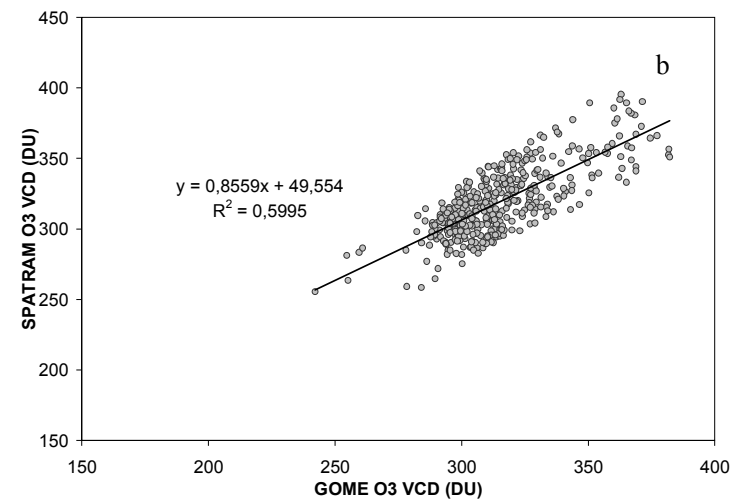

Figure 4. a) Time series of the $\mathrm{O}_{3} \mathrm{VCD}$ obtained with the SPATRAM equipment installed at Évora Observatory during 2007-2011, and the $\mathrm{O}_{3}$ data from the GOME instrument aboard the ERS-2 satellite. b) The correspondent scatter plot of the $\mathrm{O}_{3}$

data from the GOME instrument versus $\mathrm{O}_{3}$ SPATRAM data retrieved at the same period including the regression line (black line).

From the analysis of Figures 3 and 4 and it is possible to infer that SPATRAM data-set is consistent with the SCIAMACHY and GOME data presenting the same seasonal pattern. By the analysis of the scatter plot (Figures $3 \mathrm{~b}$ ) and $4 \mathrm{~b}$ )) one can see that the correlation between the two dataset is in fairly agreement with a correlation of $\mathrm{R}^{2}=0.63$ and $\mathrm{R}^{2}=0.59$, respectively. The deviation from the first satellite sensor associated is about $4,15 \%$ and for the second is $4.23 \%$ calculated using the relative error method.

\subsection{Statistical analysis}

The evaluation of some statistical parameters is made. The presented parameters are related to the comparison of SPATRAM data with data from each one of the satellite instruments. The values are presented in Table 1 and concern to the number of data $(\mathrm{N})$, the slope and the correlation coefficient $\left(\mathrm{R}^{2}\right)$ of the scatter plots and the Root Mean Square Error (RMSE). This latter parameter is frequently used to represent the sample standard deviation of the differences between predicted values (in a model) and observed values (in the real atmosphere). The RMSE is a measure of the spread of data around the regression line and is calculated using Equation 4:

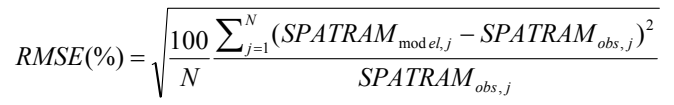

where

SPATRAM $M_{\text {obs }}=$ observed values of TOC

SPATRAM $M_{\text {model }}=$ modelled values calculated using the equation of regression line of the scatter plots (Equation 5)

$$
\text { SPATRAM } M_{\bmod e l, j}=a+b \cdot \text { Sat.Sensor }_{j}
$$

where $a=$ slope of scatter plot,

$$
b=\text { intercept of scatter plot }
$$

Sat.Sensor $=$ values available from the sensors (SCIAMACHY and GOME) aboard the satellites.
In Table 1 the Mean Bias Error (MBE) and the Mean Absolute Bias Error (MABE) are also presented which are two statistical parameters computed using Equations 6 and 7.

$$
\begin{gathered}
\operatorname{MBE}(\%)=\frac{100}{N} \sum_{j=1}^{N} \frac{\text { SPATRAM }_{j}-\text { Sat. Sensor }_{j}}{\text { Sat } . \text { Sensor }_{j}} \\
\operatorname{MABE}(\%)=\frac{100}{N} \sum_{j=1}^{N} \frac{\mid \text { SPATRAM }_{j}-\text { Sat } . \text { Sensor }_{j} \mid}{\text { Sat.Sensor }_{j}}
\end{gathered}
$$

\begin{tabular}{|l|l|l|l|l|l|l|}
\hline & N & Slope & $\mathbf{R}^{2}$ & $\begin{array}{l}\text { RMSE } \\
(\%)\end{array}$ & MBE(\%) & MABE(\%) \\
\hline SCIAMACHY & 405 & 0.89 & 0.63 & 5.25 & $-1.03 \pm 0.24$ & $4.15 \pm 0.14$ \\
\hline GOME & 409 & 0.86 & 0.60 & 5.49 & $-1.15 \pm 0.24$ & $4.24 \pm 0.13$ \\
\hline
\end{tabular}

Table 1. Correlation analysis of SPATRAM, GOME and SCIAMACHY total ozone data for the period of 2007-2011.

From the analysis of Table 1 it can be inferred that in most days the SPATRAM values are lower than the ones obtained with other sensors. Therefore there is an underestimation of the SPATRAM instrument that can be seen by the negative sign in MBE values.

The differences found between the results for TOC obtained with SPATRAM, SCIAMACHY and GOME instruments could be due to several facts such as:

- the satellite data presented above refers to the $\mathrm{O}_{3}$ total column values corresponding to the daily overpass of the ENVISAT and ERS-2 satellites over a pixel of about $1800 \mathrm{~km}^{2}(30 \times 60 \mathrm{~km})$ and $1600 \mathrm{~km}^{2}$ (40x40 km) containing the Évora station while the SPATRAM Field Of View (FOV) covers a minor area;

- the differences of methodologies used for the retrieval of $\mathrm{O}_{3}$ columns,

- the usage of different types of instruments i.e., the comparison between data from ground based spectrometer with instruments aboard satellites and the fact of SPATRAM "looks up" while the other instruments "look down" or, in other words, the SPATRAM measures the zenith sky scattered radiation and the satellite instruments carries out measurements of the radiation back-scattered by the Earth-atmosphere system,

- the employment of different AMF correction factors.

\section{DISCUSSION}

The analysis of the $\mathrm{O}_{3}$ Total Columns retrieved with SPATRAM allowed for the study of the seasonal variation of that gas over Évora for the period 2007-2011.

The obtained TOCs were compared with the satellite data from SCIAMACHY and GOME instruments. The comparison revealed a fair agreement between the datasets proving that SPATRAM instrument (in zenith sky configuration) and the employed DOAS algorithms are a good tools for the retrieval of the concentration of these compounds.

With respect to the seasonal behavior of $\mathrm{O}_{3}$ it is possible to point out that:

a) TOC shows a sinusoidal variation through the years; 
b) the $\mathrm{O}_{3}$ seasonal trend shows a maximum in Spring months and a minimum in Autumn as expected for the midlatitudes;

c) it is possible to point out the inter-annual variability in $\mathrm{O}_{3}$ values, in the years 2008 and 2010 the autumn and spring values are lower than the ones in the same season of the other analyzed period.

\section{ACKNOWLEDGEMENTS}

The first author acknowledges a) the Fundação para a Ciência e a Tecnologia (FCT) which funded this work through the grant FCT- SFRH/BD/44920/2008 and project PTDC/AACCLI/114031/2009., b) To ISAC/CNR for the AMEFCO model c) the SCIAMACHY and GOME teams for the $\mathrm{O}_{3}$ total columns data.

\section{REFERENCES}

Bortoli, D., 2005. SPATRAM- Spectrometer for Atmospheric Tracers Measurements- A prototype Equipment for the monitoring of minor compounds of the atmosphere, $\mathrm{PhD}$ thesis, University of Évora.

Bortoli, D., Silva, A. M., Costa, M. J., Domingues, A. F., \& G. Giovanelli, 2009a. Measurements of stratospheric ozone and nitrogen dioxide at Évora, Portugal, Int. J. Remote Sens., 30 (15-16), pp.4209-4226.

Bortoli, D., Silva, A. M., Costa, M. J., Domingues, A. F., \& G. Giovanelli, 2009b. Monitoring of atmospheric ozone and nitrogen dioxide over the south of Portugal by ground based and satellite observations. Opt. Express, 17 (15),pp.1294412959.

Bortoli, D., Silva, A. M., \& Giovanelli, G., 2010. A new multipurpose UV-Vis spectrometer for air quality monitoring and climatic studies, Int. J. Remote Sens., 31(3), pp.-725.

Domingues, A.F., Bortoli, D., Antón, M., \& Silva, A.M., 2011. Ozone Seasonal Variation with Ground-Based and Satellite Equipments at Évora Observatory: Portugal During 2007-2010, In Lecture Notes in Geoinformation and Cartography, edited by Jukka M. Krisp, Liqiu Meng, Roland Pail, Uwe Stilla, Proceedings of Earth Observation of Global Changes (EOGC)(Springer-Verlag Berlin Heidelberg 2013), pp.137-146.

Eskes H. J., Van der A, R. J., \& Brinksma, E., 2006. Algorithm Document TOSOMI http://www.temis.nl/docs/AD TOSOMI.pdf (20 august 2014).

Laj, P., et al., 2009. Measuring atmospheric composition change. Atmos. Environ. , 43(33), pp. 5351-5414.

Petritoli, A., Ravegnani, F., Giovanelli, G., Bortoli, D., Bonafe, U., Kostadinov, I., \& Oulanovsky, A., 2002. Off-axis measurements of atmospheric trace gases by use of an airborne ultraviolet-visible spectrometer. Appl. Opt., 41 (27), pp.55935599.

Seinfeld, J. H., Pandis, S. N., 2006. Atmospheric Chemistry and Physics: From air pollution to climate change. Wiley, New Jersey: $2^{\text {nd }}$ edition, pp.33-38.
Slusser, J., et al., 1996. Comparison of air mass computations. J. Geophys. Res.,.101, pp.9315-9321.

Valks, P.J.M., de Haan, J.F., Veefkind, J.P., van Oss, R.F., \& D.S. Balis, 2004. TOGOMI: An improved total ozone retrieval algorithm for GOME, XX Quadrennial Ozone Symposium, $1 / 6 / 2004-8 / 6 / 2004$, C.S. Zerefos (Ed), Athens, University of Athens, pp. 129-130. 